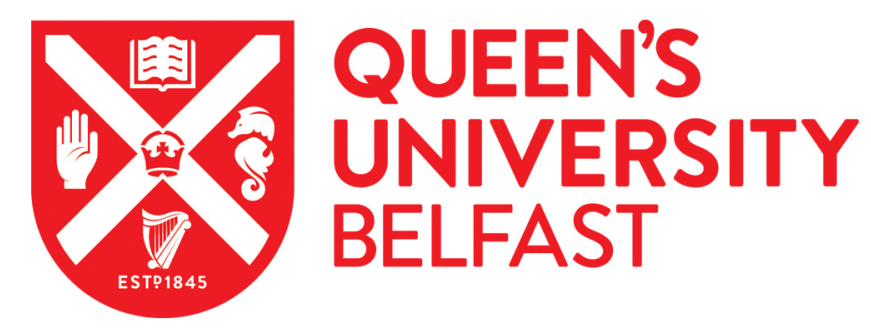

\title{
A non-opioid analgesic implant for sustained post-operative intraperitoneal delivery of lidocaine, characterized using an ovine
} model

Svirskis, D., Procter, G., Sharma, M., Bhusal, P., Dravid, A., MacFater, W., Barazanchi, A., Bennet, L., Chandramouli, K., Sreebhavan, S., Agarwal, P., Amirapu, S., Hannam, J. A., Andrews, G. P., Hill, A., \& Jones, D. S. (2020). A non-opioid analgesic implant for sustained post-operative intraperitoneal delivery of lidocaine, characterized using an ovine model. Biomaterials, 263, [120409]. https://doi.org/10.1016/j.biomaterials.2020.120409

Published in:

Biomaterials

Document Version:

Publisher's PDF, also known as Version of record

Queen's University Belfast - Research Portal:

Link to publication record in Queen's University Belfast Research Portal

\section{Publisher rights}

() 2020 The Authors.

This is an open access article published under a Creative Commons Attribution-NonCommercial-NoDerivs License

(https://creativecommons.org/licenses/by-nc-nd/4.0/), which permits distribution and reproduction for non-commercial purposes, provided the author and source are cited.

\section{General rights}

Copyright for the publications made accessible via the Queen's University Belfast Research Portal is retained by the author(s) and / or other copyright owners and it is a condition of accessing these publications that users recognise and abide by the legal requirements associated with these rights.

\section{Take down policy}

The Research Portal is Queen's institutional repository that provides access to Queen's research output. Every effort has been made to ensure that content in the Research Portal does not infringe any person's rights, or applicable UK laws. If you discover content in the Research Portal that you believe breaches copyright or violates any law, please contact openaccess@qub.ac.uk. 


\title{
A non-opioid analgesic implant for sustained post-operative intraperitoneal delivery of lidocaine, characterized using an ovine model
}

\author{
Darren Svirskis ${ }^{\mathrm{a}, *}$, Georgina Procter ${ }^{\mathrm{b}}$, Manisha Sharma ${ }^{\mathrm{a}}$, Prabhat Bhusal ${ }^{\mathrm{a}}$, Anusha Dravid ${ }^{\mathrm{a}}$, \\ Wiremu MacFater ${ }^{\mathrm{c}}$, Ahmed Barazanchi ${ }^{\mathrm{c}}$, Laura Bennet ${ }^{\mathrm{d}}$, Kaushik Chandramouli ${ }^{\mathrm{a}}$, \\ Sree Sreebhavan ${ }^{\mathrm{e}}$, Priyanka Agarwal ${ }^{\mathrm{a}}$, Satya Amirapu ${ }^{\mathrm{f}}$, Jacqueline A. Hannam ${ }^{\mathrm{g}}$, \\ Gavin P. Andrews ${ }^{\mathrm{b}}$, Andrew Hill ${ }^{\mathrm{c}}$, David S. Jones ${ }^{\mathrm{b}}$ \\ ${ }^{a}$ School of Pharmacy, Faculty of Medical and Health Sciences, University of Auckland, Private Bag, 92019, Auckland, New Zealand \\ ${ }^{\mathrm{b}}$ School of Pharmacy, Queen's University Belfast, Belfast, United Kingdom \\ ${ }^{c}$ South Auckland Clinical School, Faculty of Medical and Health Sciences, University of Auckland, Private Bag, 92019, Auckland, New Zealand \\ ${ }^{\mathrm{d}}$ Department of Physiology, Faculty of Medical and Health Sciences, University of Auckland, Private Bag, 92019, Auckland, New Zealand \\ ${ }^{\mathrm{e}}$ Faculty of Medical and Health Sciences, University of Auckland, Private Bag, 92019, Auckland, New Zealand \\ ${ }^{\mathrm{f}}$ School of Medicine, Faculty of Medical and Health Sciences, University of Auckland, Private Bag, 92019, Auckland, New Zealand \\ ${ }^{g}$ Department of Pharmacology \& Clinical Pharmacology, Faculty of Medical and Health Sciences, University of Auckland, Private Bag, 92019, Auckland, New Zealand
}

\section{A R T I C L E I N F O}

\section{Keywords:}

EVA

Co-extrusion

Pain

Opioid-sparing

Controlled release

\begin{abstract}
A B S T R A C T
Appropriate management of post-operative pain is an ongoing challenge in surgical practice. At present, systemic opioid administration is routinely used for analgesia in the post-operative setting. However, due to significant adverse effects and potential for misuse, there is a perceived need for the development of alternative, opioidsparing treatment modalities. Continuous infusion of local anesthetic into the peritoneum after major abdominal surgery reduces pain and opioid consumption, and enhances recovery from surgery. Here we describe a nonopioid, poly(ethylene-co-vinyl-acetate) intraperitoneal implant for the sustained delivery of local anesthetic following major abdominal surgery. A radio-opaque core had the required mechanical strength to facilitate placement and removal procedures. This core was enclosed by an outer shell containing an evenly dispersed local anesthetic, lidocaine. Sustained release of lidocaine was observed in an ovine model over days and the movement modelled between peritoneal fluid and circulating plasma. While desirably high levels of lidocaine were achieved in the peritoneal space these were several orders of magnitude higher than blood levels, which remained well below toxic levels. A pharmacokinetic model is presented that incorporates in vitro release data to describe lidocaine concentrations in both peritoneal and plasma compartments, predicting similar release to that suggested by lidocaine concentrations remaining in the device after 3 and 7 days in situ. Histological analysis revealed similar inflammatory responses following implantation of the co-extruded implant and a commercially used silicone drain after three days. This non-opioid analgesic implant provides sustained release of lidocaine in an ovine model and is suitable for moving onto first in human trials.
\end{abstract}

\section{Introduction}

Surgical treatment is an integral facet of disease management, with an estimated 312 million surgical procedures performed worldwide in 2012 alone [1]. Despite advances over the past decades, inadequate management of post-operative pain remains an unresolved clinical issue [2]. Suboptimal pain control has been shown to potentiate undesirable outcomes following surgery, including: reduced wound healing [2], increased mortality [3], and the development of medical complications (e.g. pneumonia, chronic pain) [4]. Currently, systemic opiate administration is the mainstay therapy for severe post-operative pain control. However, the risk of developing significant adverse effects (e.g. sedation, respiratory depression, gastrointestinal and bladder dysfunction) in conjunction with the long-term potential for misuse, diversion, and addiction necessitates careful precaution and monitoring [5]. In fact, certain countries have found opioid-associated harm reaching near

\footnotetext{
* Corresponding author.

E-mail address: d.svirskis@auckland.ac.nz (D. Svirskis).
} 
Table 1

Inner core (Killion $25 \mathrm{~mm}$ single screw extruder) and outer core (Dr Collin ZK 25 twin screw extruder) processing conditions for the bilayer co-extrudate.

\begin{tabular}{|c|c|c|c|c|c|c|c|c|c|}
\hline \multirow{2}{*}{ Core } & \multirow[b]{2}{*}{ Feed Zone } & \multirow{2}{*}{ Zone 1} & \multicolumn{5}{|l|}{ Temperature $\left({ }^{\circ} \mathrm{C}\right)$} & \multirow[t]{2}{*}{ Screw Speed (RPM) } & \multirow[t]{2}{*}{ Pressure (PSI) } \\
\hline & & & Zone 2 & Zone 3 & Zone 4 & Zone 5 & Die & & \\
\hline Inner & 80 & 100 & 115 & 110 & 100 & 95 & 90 & 6 & 820 \\
\hline Outer (no drug) & 70 & 90 & 90 & 90 & 90 & 90 & 90 & 70 & 60 \\
\hline Outer (drug) & 45 & 65 & 65 & 65 & 65 & 65 & 90 & 70 & 0 \\
\hline
\end{tabular}

epidemic levels, with the mortality from opioids more than tripling over the past two decades [6]. As such, there is a vested global interest in the development of alternative, non-opioid modalities to provide post-operative pain relief.

Lidocaine is a local anesthetic, chemically known as 2-(diethylamino)-N-(2,6-dimethylphenyl)-acetamide, with a molecular weight of $234.34 \mathrm{~g} / \mathrm{mol}$. Like other local anesthetics, its mechanism of action involves the blockade of voltage-gated sodium channels to prevent the flux of sodium ions across the neuron. This results in decreased neuronal depolarization and failure to transmit an action potential, creating an anesthetic effect through inhibition of nociceptive signal transmission [7]. Lidocaine has a short half-life, which limits the period of effectiveness following administration of a single dose [8]. Recent investigations have described the potential of addressing the pain and resulting post-operative fatigue from major abdominal surgery by using local anesthetics to reduce vagal nerve activation. Specifically, it has been shown that continuous intraperitoneal infusion of local anesthetic over $72 \mathrm{~h}$ reduced pain and fatigue, in addition to enhancing functional recovery [9]. Lidocaine is the local anesthetic of choice in this work due to its favorable toxicity profile, and rapid elimination from the body. While other local anesthetics are often favored in peri-operative use due to their longer half-lives, we have intentionally selected lidocaine with a relatively short half-life. The formulation described in this work achieves sustained release, therefore a longer acting local anesthetic is not required. The use of lidocaine provides assurance that in the rare event of an adverse drug reaction the formulation can be removed from the body and the drug will be quickly eliminated. There is no consensus as to the dosing of intraperitoneal lidocaine to reduce postoperative pain, generally doses below $1 \mathrm{~g}$ of lidocaine are used [10-12].

Constant infusion of local anesthetics into the peritoneal cavity is generally achieved with the aid of an elastomeric pump (i.e. PainBuster $\left.{ }^{\circledR}\right)$, or other infusion device. Long-term use of such infusion devices requires ongoing monitoring by trained health professionals [13] and is associated with a risk of infection [14], pump failure and instability [15] whilst being exteriorized. Other opioid-sparing drug delivery systems have been explored to prolong post-operative analgesia over several days [16]. This includes the collagen-based matrix XARACOLL ${ }^{\circledR}$, and the injectable systems POSIMIR $®$ and liposomal EXPAREL $\AA$, of which only the last is FDA-approved. However, in the event of an adverse reaction or toxicity, it is essential that the dosage form can be removed from the body. For the systems described above, this is often not feasible and the depot release must run its course.

Non-biodegradable implants for sustained drug delivery remain intact within the body and permit early removal if toxicity were to develop [17]. Drug release from the implant is governed by diffusion from the matrix or through a polymer membrane, and is particularly useful when reliable controlled release of a drug over a relatively longer period is required. Poly(ethylene-co-vinyl-acetate) (EVA) is a thermoplastic co-polymer biomaterial widely used for implant fabrication [18]. The biocompatibility of EVA has been well demonstrated, with proven application for the delivery of pilocarpine (Ocusert ${ }^{\circledR}[19]$ ), progesterone (Progestasert ${ }^{\circledR}[20]$ ), etonogestrel (Implanon ${ }^{\circledR}[21]$ ), etonogestre1/ethinylestradiol (NuvaRing ${ }^{\circledR}[22]$ ), tetracycline (Actisite ${ }^{\circledR}[23]$ ), sirolimus (Cypher ${ }^{\circledR}[24]$ ) and ganciclovir (Vitrasert $\left.{ }^{\circledR}[25]\right)$. Its structure comprises a random polymerization of poly vinyl acetate (VA) along with poly ethylene [18]. The physical properties of EVA depend upon the proportions of these two components, enabling the polymer to vary in crystallinity and stiffness. When the VA composition increases relative to the ethylene proportion, the amorphous state of EVA increases, decreasing the overall rigidity of the polymer.

In the present work, we describe a novel EVA-based implantable device to sustain lidocaine delivery suitable for use in post-operative analgesia, demonstrated in an ovine model. A co-extrusion approach was used to prepare the EVA based implant, with a drug-loaded shell and a core enabling the required tensile strength and radio-opacity for clinical use. We have proven the potential of this device to be a safe, nontoxic approach to achieve localized administration of analgesics into the peritoneal cavity over a sufficient period for pain control following major abdominal surgery.

\section{Materials and methods}

\subsection{Materials}

Lidocaine, myristic acid and barium sulfate $\left(\mathrm{BaSO}_{4}\right)$ were purchased from Taresh Ltd (Banbridge, UK). Lauric acid was purchased from Sigma Aldrich (St. Louis, MO, USA). Nitrolidocaine was purchased from TRC Canada (Ontario, Canada). Dichloromethane was purchased from Merck KgaA, Darmstadt, Germany, methanol from Fisher Scientific, Fair Lawn, NJ, US and acetonitrile from Merck, Auckland, New Zealand. EVA (Ateva 3325 [comprising a 33\% VA component] and Ateva 1241 [12\% VA]) was provided by Celanese (Edmonton, Alberta, Canada).

\subsection{Manufacture of EVA implants}

EVA implants were manufactured by hot melt co-extrusion with a core/shell structure, according to the processing conditions shown in Table 1 . The inner core comprising $80 \% \mathrm{w} / \mathrm{w}$ EVA $(12 \% \mathrm{VA})$ and $20 \%$ $\mathrm{w} / \mathrm{w} \mathrm{BaSO}_{4}$ conferred the device with the desired mechanical strength and radio-opacity required to facilitate implantation and handling. The outer layer formed from EVA (33\% VA) was loaded with $20 \% \mathrm{w} / \mathrm{w}$ lidocaine stabilized with myristic acid. Without myristic acid, and at loading levels above $10 \% \mathrm{w} / \mathrm{w}$ lidocaine base in EVA (33\% VA), drug is physically unstable in the polymer carrier and rapidly crystalizes on the surface. For controls, blank implants were prepared with the same inner core but with the outer layer devoid of lidocaine and myristic acid. The bilayer strand was produced using a modified over coating cross head die, with the inside strand fed from a Killion $25 \mathrm{~mm}$ single screw extruder and the outer layer fed from a Dr Collin ZK 25 twin screw extruder. We have previously demonstrated the thermal stability of lidocaine [26]. The strand was cooled in the short water cooling section of the Dr Collin tube line, with the die in the horizontal position.

\subsection{Co-extrudate dimensions and theoretical drug loading}

Co-extrudate samples were visualized using a Leica EZ4W Stereo Microscope (Milton Keynes, UK) equipped with Leica LAS EZ software to determine the dimensions. For each sample $(n=3)$, four measurements were recorded for the inner core diameter and the outer layer width. The mean values for these measurements were then used to calculate the total diameter.

While the drug loaded outer layer contained $20 \% \mathrm{w} / \mathrm{w}$ lidocaine, the theoretical drug loading of the total co-extrudate was calculated by weighing $1 \mathrm{~cm}$ samples of co-extrudate $(\mathrm{n}=3)$. The total radius and 
radius of the inner core was used to calculate the volumes of the different layers. Assuming a density of $1 \mathrm{~g} \mathrm{~cm}^{-3}$, the theoretical weight of the inner core was calculated and the theoretical weight of the outer layer was calculated by subtracting the theoretical weight of the inner core from the actual weight of the total co-extrudate.

\subsection{Drug content uniformity}

Evaluation of drug content uniformity was conducted to assess the consistency of the extruded preparation and to ensure that segments of the extrudate contain the same proportions of lidocaine [27]. Three samples $(\sim 50 \mathrm{mg})$ were taken from evenly separated locations of the extruded polymer. The samples were added to $50 \mathrm{~mL}$ of dichloromethane (DCM) and sonicated for $40 \mathrm{~min}$ to dissolve the EVA and lidocaine. Following dissolution, a $1 \mathrm{~mL}$ aliquot of the resulting solution was withdrawn and added to a volumetric flask. The DCM was evaporated from the solution by heating at $60{ }^{\circ} \mathrm{C}$ for $60 \mathrm{~min}$. Lidocaine was dissolved from the resulting drug film by adding $10 \mathrm{~mL}$ of methanol and sonication for $30 \mathrm{~min}$. The methanolic solutions containing lidocaine were centrifuged to remove the insoluble EVA. The remaining solution was quantified for lidocaine using high-performance liquid chromatography (HPLC), as previously described [26].

\subsection{Raman mapping following co-extrusion}

To elucidate the distribution of the lidocaine in the core and outer layer, Raman mapping of the co-extrudate was conducted using the RamanStation R3 (Avalon Instruments, Belfast, UK). Samples were placed on aluminum foil covering a glass slide and the slide subsequently mounted into the Raman stage. A $785 \mathrm{~nm}$ laser $(300 \mathrm{~mW})$ was applied and analysis was performed between 200 and $3200 \mathrm{~cm}^{-1}$. The exposure time and number of exposures was $5 \mathrm{~s}$ and 4 , respectively. The following parameters were used: $0.2 \mathrm{~mm}$ spacing and 25 points (width and height), eliciting a map of $4.8 \times 4.8 \mathrm{~mm}$. The mapping was performed by comparing the correlation of the individual points on the sample map to a lidocaine reference spectra at a $1541-1708 \mathrm{~cm}^{-1}$ Raman shift range for comparison, as this region was void of EVA peaks but contained significant lidocaine Raman shift peaks.

\subsection{Release of lidocaine from EVA melt extrudate}

In vitro release data was generated to support pharmacokinetic analysis. Lidocaine release from a single strand of HME EVA (33\% VA) containing $20 \%$ lidocaine stabilized with myristic acid in peritoneal fluid, containing $6 \mathrm{mM}$ of sodium azide as preservative was determined. We have previously determined the solubility of lidocaine in biological fluid and can confirm these experiments were conducted under sink conditions [27]. Peritoneal fluid was obtained from a human patient (Health and Disability Ethics Committee (HDEC, Wellington, New Zealand) approval 15/CEN/30). Falcon tubes containing the extrudate with peritoneal fluid were agitated in a $37{ }^{\circ} \mathrm{C}$ water bath (40 oscillations per minute). The extrudate was wrapped with stainless steel mesh to ensure it was submerged in the media at all times. Lidocaine was extracted from peritoneal fluid and quantified by HPLC using previously reported methods [26].

\section{Table 2}

In vivo study group descriptions.

\begin{tabular}{llll}
\hline Group & Number of Sheep & Extrudate Type & Length of Implantation (days) \\
\hline 1 & 5 & Drug loaded & 7 \\
2 & 3 & Blank & 7 \\
3 & 3 & Drug loaded & 3 \\
\hline
\end{tabular}

\subsection{In vivo ovine surgical procedure, implant placement and maintenance}

The safety and toxicity of the implants were determined in adult sheep. All procedures were approved by the Animal Ethics Committee of the University of Auckland (ethics number 1657), and carried out in accordance with the New Zealand Animal Welfare Act 1999 and the University of Auckland's Code of Ethical Conduct for the use of animals for teaching and research. This manuscript is compliant with the ARRIVE guidelines for reported animal research [28].

Eleven Romney ewes were acclimatized to the laboratory for a week, during which time routine veterinary health and welfare checks were performed. Food, but not water, was withdrawn $12-18 \mathrm{~h}$ before surgery to reduce the risk of aspiration during surgery. Immediately before surgery, ewes were weighed for anesthetic drug dose calculations, and given an intramuscular injection of the antibiotic oxytetracycline (20 $\mathrm{mg} / \mathrm{kg}$, Phoenix Pharm, Auckland, New Zealand) for prophylaxis. Ewes were anesthetized by an intravenous injection of propofol $(5 \mathrm{mg} / \mathrm{kg}$; AstraZeneca Limited, Auckland, New Zealand), intubated and general anesthesia was maintained using 2-3\% isoflurane in $\mathrm{O}_{2}$ (Bomac Animal Health, NSW, Australia). While under anesthesia fluid balance was maintained via a constant saline infusion $(\sim 250 \mathrm{~mL} / \mathrm{h})$. Animals were constantly monitored by trained anesthetic technicians throughout surgery.

All procedures were performed using sterile techniques. Surgical fields were shaved and cleaned with a betadine solution (Southern Veterinary Supplies, Hamilton, New Zealand), and draped with sterile linen. Using a scalpel and diathermy, a midline incision was made and a segment of jejunum was identified for resection. A $5 \mathrm{~cm}$ segment of small bowel was resected. The mesentery was ligated using 2-0 silk. The small bowel ends were spatulated and inspected for adequate blood supply. An end to end hand-sewn anastomosis was performed with 3-0 polydioxanone (PDS). The anastomosis was then inspected for any defects and leak tested using the small bowel content. Any defects noted were secured using a single interrupted 3-0 PDS. The mesenteric defect was closed using the same PDS suture in a loose continuous fashion. The bowel was then re-introduced into the abdominal cavity and orientation was corrected as much as possible. A 15 French silicone fluted Blake drain was placed on the left lateral side of the sheep and spigotted. A second tract was created parallel to the Blake drain for the implant. Immediately before administration all implants were dipped in $96 \%$ ethanol and allowed to dry. One length of the implant $(40 \mathrm{~cm})$ was passed through this tract and protruded for $5 \mathrm{~mm}$ from the surface of the skin. 2-0 silk was used to secure both the drain and implant. Three more lengths of the implant were then placed inside the peritoneal cavity and fixed to the peritoneum right lateral of the laparotomy wound. The total length of implant administered was therefore $159.5 \mathrm{~cm}$. The fascia was sutured closed with linen umbilical tape followed by the skin with 30 silk. A central venous catheter, prepared with heparinized saline, was then placed into the left internal jugular using the Seldinger technique [29]. The line was secured using 3-0 silk.

On completion of the surgical procedures, the sheep were extubated, transferred to pens and monitored until they were able to stand to reach food and water. Rooms were temperature-controlled $\left(16 \pm 1{ }^{\circ} \mathrm{C}\right.$, humidity $50 \pm 10 \%$ ) with a $12 \mathrm{~h}$ light/dark cycle. Ewes were provided with water and food (concentrated pelleted food, Dunstan Nutrition, Hamilton, New Zealand) ad libitum. When required, molasses and hay were used to encourage eating (Southern Veterinary Supplies, Hamilton, New Zealand).

Blood samples were obtained postoperatively at $1 \mathrm{~h}, 2 \mathrm{~h}, 4 \mathrm{~h}, 6 \mathrm{~h}, 1$ day, 2 days, 3 days, 5 days and 7 days for the first eight procedures using the central venous line. The line was locked with heparinized saline after each use. Peritoneal samples were also obtained at the same time points from the abdominal drain for as long as the drain was patent. The drain was spigotted after each use. The drain also served as a comparator material to evaluate the foreign body response. For the final 3 sheep blood samples and peritoneal samples were obtained at $1 \mathrm{~h}, 2 \mathrm{~h}, 4 \mathrm{~h}, 6 \mathrm{~h}$, 
Table 3

Histopathological grading criteria for inflammation, granulation and fibrosis.

\begin{tabular}{lll}
\hline Score & Inflammation & Granulation and Fibrosis \\
\hline $\mathbf{0}$ & No inflammatory cells & No granulation tissue \\
$\mathbf{1}$ & Restricted to surface of tract & Restricted to surface of tract \\
$\mathbf{2}$ & Extension into muscle & Radiating to dermis \\
$\mathbf{3}$ & Fat infiltration & Radiating to muscle \\
$\mathbf{4}$ & - & Extension to fat \\
\hline
\end{tabular}

1 day, 2 days and 3 days.

In total, 5 sheep received the drug loaded implant for 7 days and 3 sheep received the blank implant for 7 days (Table 2). Additionally, a further 3 sheep received drug loaded implants for 3 days. Sheep were euthanized at day 3 or day 7 post-implantation by an overdose of sodium pentobarbital delivered intravenously to the ewe (9 g Pentobarb 300, Chemstock International, Christchurch, New Zealand). The peritoneal cavity was subsequently opened to recover tissues from the implant and drain site.

\subsection{Histopathology}

The peritoneal tissue recovered at post-mortem was stained with haematoxylin and histopathological images were examined by a blinded observer. The extent of inflammation in tissue and granulation tissue and fibrosis at implant and drain site in each sheep was graded as described in Table 3.

\subsection{Determination of lidocaine and myristic acid in blood and peritoneal fluid}

Samples were centrifuged at $5844 \times g$ for $10 \mathrm{~min}$ to remove cells and debris. Plasma and peritoneal fluid were collected and stored at $-20^{\circ} \mathrm{C}$. The stability of lidocaine in plasma has previously been demonstrated in the literature [28]. Extraction of lidocaine and myristic acid from the biological samples was performed by adding $800 \mu \mathrm{L}$ of acetonitrile and $100 \mu \mathrm{L}$ of water to $100 \mu \mathrm{L}$ of the sample to precipitate the proteins. The resulting solutions were vortexed and allowed to stand overnight before centrifuging at $5844 \times g$ for $10 \mathrm{~min}$. The resulting supernatant was withdrawn and analyzed by liquid chromatography with tandem mass spectrometry (LCMS-MS), details are given in the supplementary information.

\subsection{Pharmacokinetic analysis}

Pharmacokinetic modelling was used to relate in vivo lidocaine release with that observed in vitro, and to provide an initial model for future study planning. Full details are given in the supplementary material but briefly, parameters for lidocaine absorption into the peritoneal from the implant were estimated from in vitro data of lidocaine release (see Section 2.8). These parameters were fixed for in vivo data analysis and included a first order release rate constant from the implant to peritoneal (Krel), bioavailability (F) and the fraction of drug released instantaneously from the implant (F_bol). First order drug absorption between peritoneal and plasma was assumed with first order elimination occurring from both peritoneal (e.g. drug metabolism or loss via the liver or lymphatic drainage) and plasma. The model was parameterized in terms of clearance $(\mathrm{CL} / \mathrm{F})$ and volume of distribution $(\mathrm{V} / \mathrm{F})$. Population parameter variability was described using exponential models, which is equivalent to assuming a log-normal distribution. Additive and proportional error models were used to describe unknown PK residual error. Data were analyzed using $\mathrm{R}$ version 3.6.1 with $\mathrm{R}$ Studio (RStudio Team (2016). RStudio: Integrated Development for R. RStudio, Inc., Boston, MA) and nonlinear mixed effects models (NONMEM 7.4, Globomax LLC, Hanover, MD, USA). Non-parametric bootstrap methods were used to estimate confidence intervals to evaluate parameter uncertainty [30] and visual predicted checks (VPC) [31] were used to evaluate how well the model predicted the distribution of observations.

\subsection{Lidocaine and myristic acid remaining post-implantation}

Lidocaine and myristic acid remaining in the co-extrudate samples recovered at day 3 or day 7 post-implantation was determined by LCMSMS. The sample preparation method was similar to that used for determining uniformity of drug content. From each sheep, three sections of the implant $(1 \pm 0.2 \mathrm{~cm})$ were removed, ensuring to avoid regions tied with sutures. Components of the outer coating were dissolved by sonication in DCM and the resulting volume made up to $50 \mathrm{~mL}$. A $2 \mathrm{~mL}$ aliquot of this solution was dried at $60^{\circ} \mathrm{C}$ for $1 \mathrm{~h}$ and reconstituted in 10 $\mathrm{mL}$ methanol. The methanolic solutions were diluted and assayed by LCMS-MS, details are given in the supplementary information.

\subsection{Tensile strength}

The tensile strength analysis of the implant was determined using the TA.XT Plus Texture Analyser (Stable Microsystems, USA) to ensure its mechanical strength was sufficient to facilitate surgical implantation, integrity in the peritoneum and removal. Extrudate samples $(\sim 30 \mathrm{~mm}$ long) were prepared and the diameter of each sample determined using digital calipers with an average of five readings recorded. Upon calibrating the Texture Analyser, the gauge (strain height) was set at $5 \mathrm{~mm}$ and the sample secured between the upper and lower clamps. Using a test speed of $5 \mathrm{~mm} \mathrm{~s}^{-1}$, the data of samples $(\mathrm{n}=5)$ that broke in the
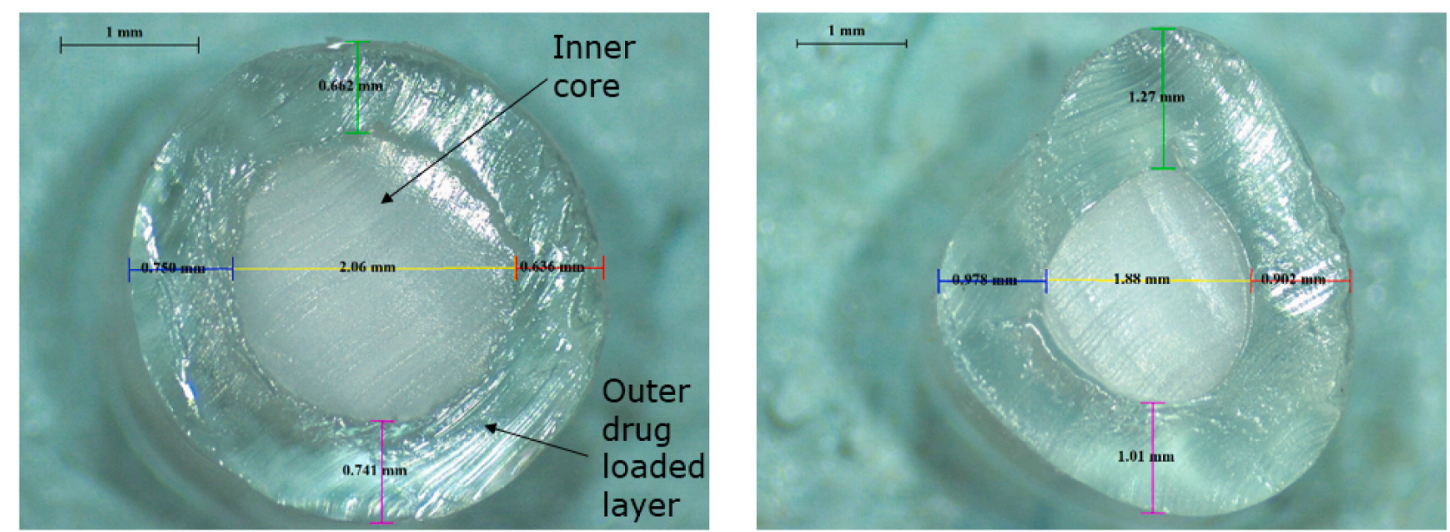

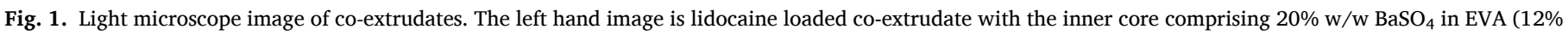

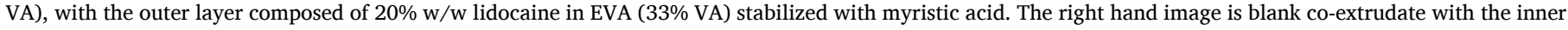
core comprising $20 \% \mathrm{w} / \mathrm{w} \mathrm{BaSO}_{4}$ in EVA (12\% VA), the outer layer is EVA (33\% VA). 
Table 4

Summary of the dimensions of the lidocaine loaded and blank co-extrudates (n $=3$ ).

\begin{tabular}{llll}
\hline Sample & $\begin{array}{l}\text { Inner Core } \\
\text { Diameter Mean } \pm \\
\text { SD (mm) }\end{array}$ & $\begin{array}{l}\text { Outer Layer } \\
\text { Thickness Mean } \pm \\
\text { SD (mm) }\end{array}$ & $\begin{array}{l}\text { Calculated Total } \\
\text { Diameter (mm) }\end{array}$ \\
\hline $\begin{array}{l}\text { Lidocaine } \\
\text { loaded } \\
\text { Co- } \\
\text { extrudate }\end{array}$ & $2.05 \pm 0.02$ & $0.71 \pm 0.04$ & 3.47 \\
$\begin{array}{c}\text { Blank } \\
\text { Co- } \\
\text { extrudate }\end{array}$ & $1.85 \pm 0.04$ & $1.03 \pm 0.15$ & 3.90 \\
\hline
\end{tabular}

middle region were recorded. The Young's modulus was calculated from the gradient of linear portion (elastic deformation) of the stress-strain curve. The tensile strength at break was determined using Equation (1).

Tensile strength at break $=\frac{\text { Force at } \operatorname{Break}(N)}{\text { Film thickness }\left(m^{2}\right)}$

Equation(1)

\subsection{Surface morphology}

Implant samples sputter coated with gold were examined under a TM3030Plus Scanning Electron Microscope (Hitachi, Tokyo, Japan) before and after surgery. Cross-sectional images were acquired using black scattered electrons (BSE), whilst surface images were acquired using a mix mode (BSE and secondary electrons) at $15 \mathrm{Kv}$. Images were acquired at magnifications ranging from $60-500 \mathrm{X}$.

\subsection{Data analysis}

Descriptive data are provided as mean \pm standard deviation (SD). Difference between mean values (or median values for histology data) of treatments were statistically determined using the Kruskal-Wallis test in conjunction with Dunn's post hoc test. In all cases $\mathrm{p}<0.05$ denoted significance. For PK analysis, model selection required a statistically significant improvement $(\mathrm{p}<0.05)$ in the NONMEM objective function between nested models, equating to a reduction $>3.84$ based on a chisquare distribution with one degree of freedom, and inspection of standard goodness of fit plots.

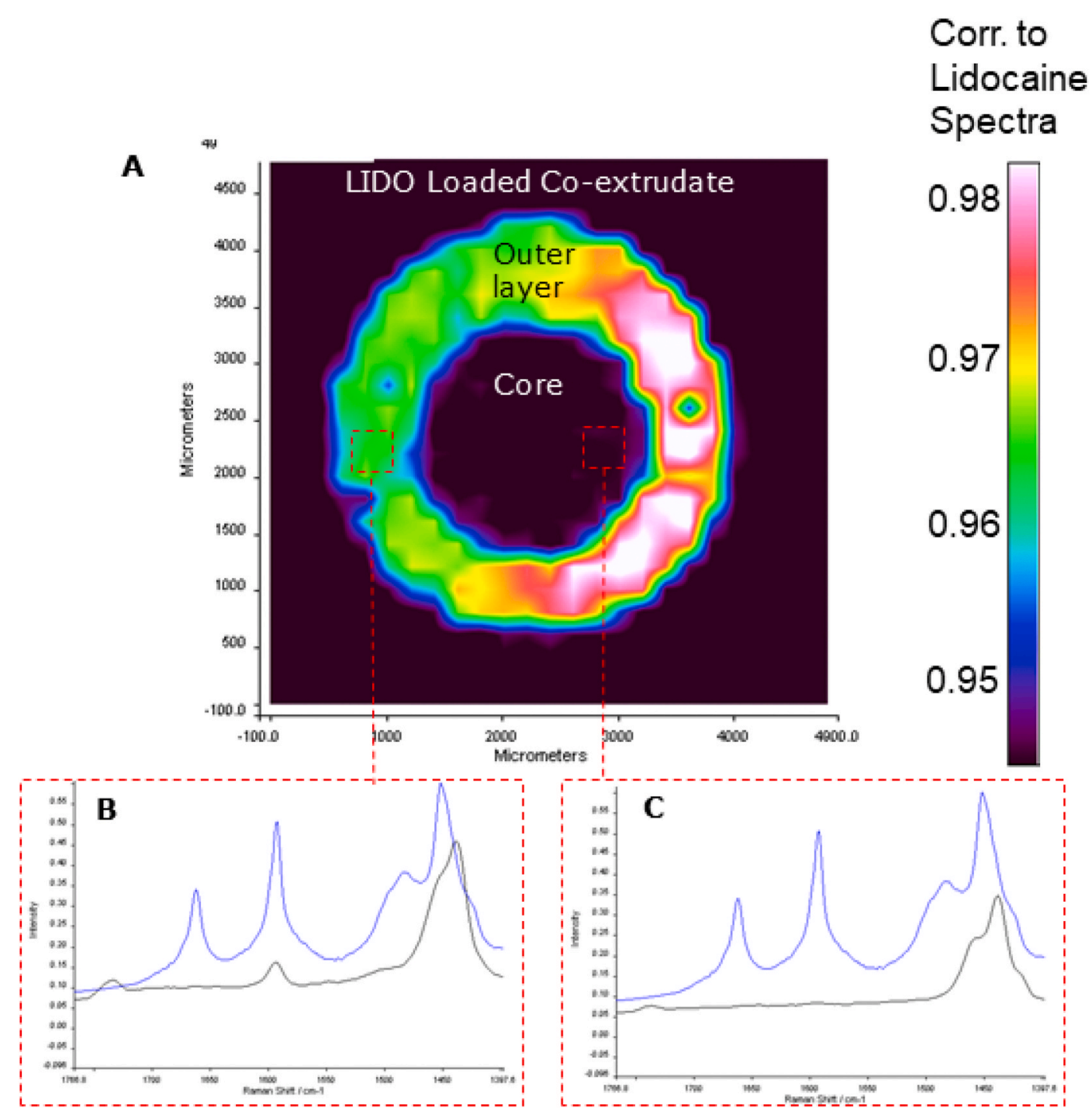

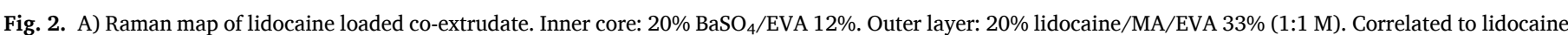

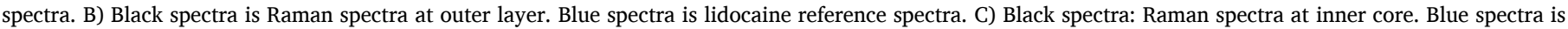
lidocaine reference spectra. (For interpretation of the references to colour in this figure legend, the reader is referred to the Web version of this article.) 

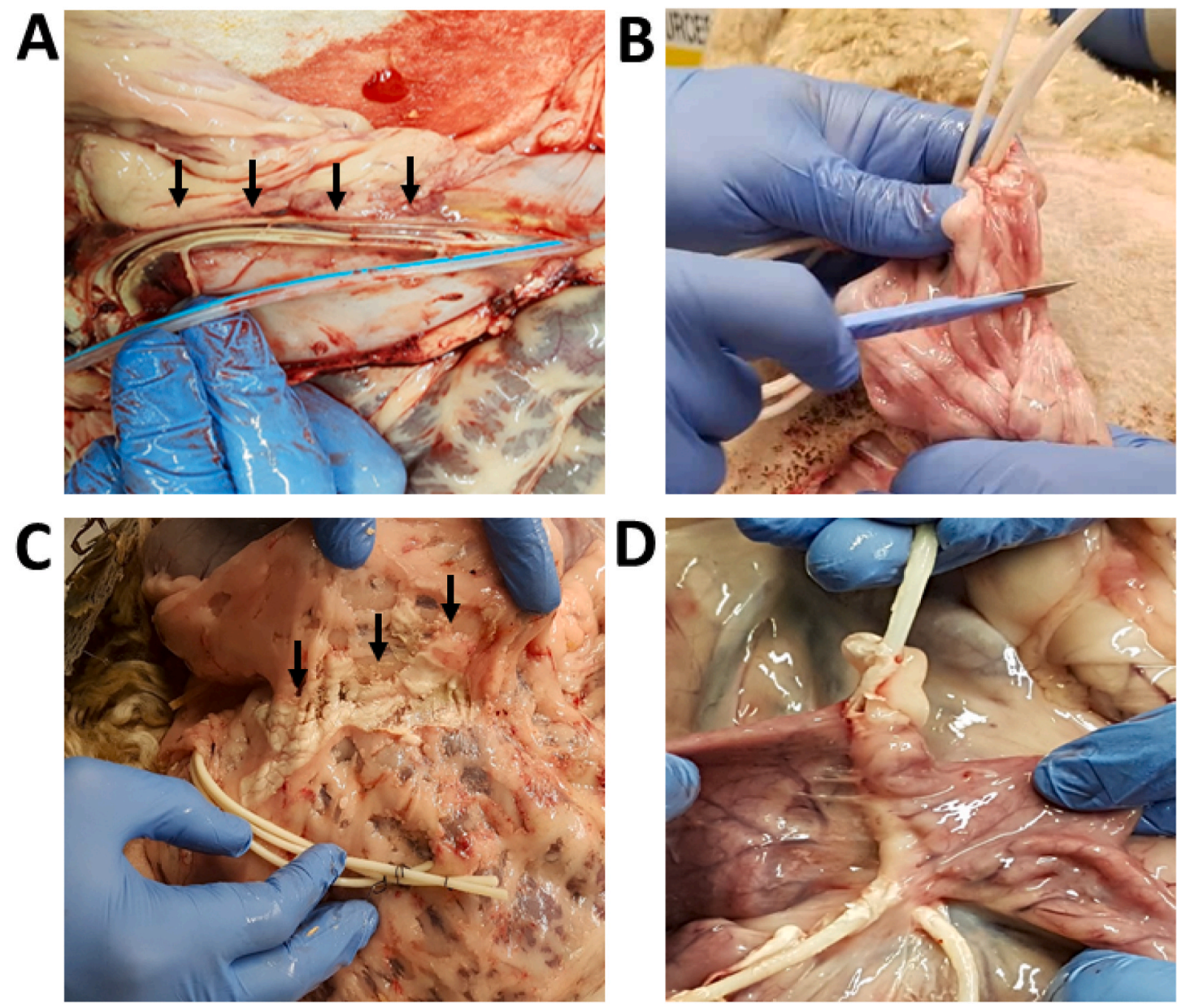

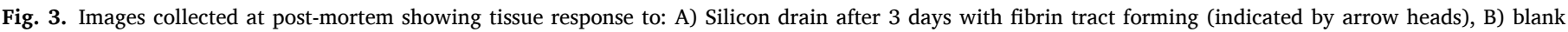

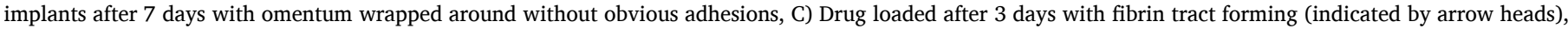

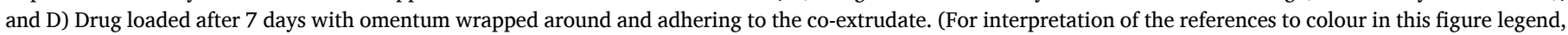
the reader is referred to the Web version of this article.)

\section{Results and discussion}

\subsection{Implant manufacture and drug content}

Fig. 1 illustrates the clear outer lidocaine loaded layer of the extrudate enclosing the white opaque inner core. The presence of $\mathrm{BaSO}_{4}$ within the inner core confers the implant with the radiopacity for radiographic identification. Table 4 reports the mean dimensions of the drug loaded and blank co-extrudates. The inner core of the lidocaine loaded co-extrudate was $2.05 \mathrm{~mm}$ and the outer layer thickness 0.71 $\mathrm{mm}$, resulting in a total diameter of $3.47 \mathrm{~mm}$. The inner core of the blank co-extrudate had a slightly smaller diameter of $1.85 \mathrm{~mm}$ and the outer layer $1.03 \mathrm{~mm}$, providing a total diameter of $3.90 \mathrm{~mm}$. The cross section was a uniform shape along the length of the implant, while the drug loaded co-extrudate had a circular cross-section, the cross-section of the blank co-extrudate resembled a rounded triangle. The differences arise, as with and without drug different processing conditions were required (Table 1) to form the co-extruded, bilayer strands.

For the drug loaded co-extrudate the mass was $0.114 \mathrm{~g}$ per $\mathrm{cm}$ of coextrudate $(\mathrm{n}=3)$. The volume of the inner core was $0.033 \mathrm{~cm}^{3}$ per $\mathrm{cm}$ of co-extrudate, and assuming a density of $1 \mathrm{~g} \mathrm{~cm}^{-3}$ the theoretical mass of the outer layer was $0.805 \mathrm{~g}$ per $\mathrm{cm}$ of co-extrudate. At $20 \% \mathrm{w} / \mathrm{w}$ drug loading in the outer shell, this yields $16.1 \mathrm{mg}$ lidocaine per $\mathrm{cm}$ of coextrudate, with a drug loading per total mass of co-extrudate of $14.1 \%$ $\mathrm{w} / \mathrm{w}$. As the total length of implant administered was $159.5 \mathrm{~cm}$, the total administered dose was $2.6 \mathrm{~g}$ of lidocaine. This dose is in-line with intraperitoneal doses of lidocaine used perioperatively in clinical trials to reduce postoperative pain following abdominal surgery [10-12].

Drug content uniformity was calculated as the percentage of theoretical lidocaine recovered and is expressed in relation to the expected drug loading, as determined from 3 samples positioned at different locations along the co-extrudate. The $\%$ theoretical lidocaine loading was $103.4 \% \pm 6.6 \%$, indicating consistent loading along the co-extrudate.

\subsection{Raman mapping}

Raman mapping was used to ascertain the spatial distribution of lidocaine within the co-extrudate and to determine if any drug migration had occurred during manufacture. As depicted in Fig. 2, an exceptionally high correlation with lidocaine was observed in the outer core. In contrast, no lidocaine was detected within the inner core, confirming that the drug had not migrated. Within the outer layer, the drug distribution was mostly even, with only minor differences.

\subsection{In vivo ovine surgery, implant placement and maintenance}

In vivo ovine studies were conducted to determine the safety and performance of the implant. All investigated sheep made it to the experimental endpoint. Lidocaine implants that remained in situ for 7 days, had significant fibrin tracts forming within their vicinity and active inflammation was seen on the omentum (Fig. 3D), particularly in comparison to the blank implants (Fig. 3B) and silicone drains. For this 

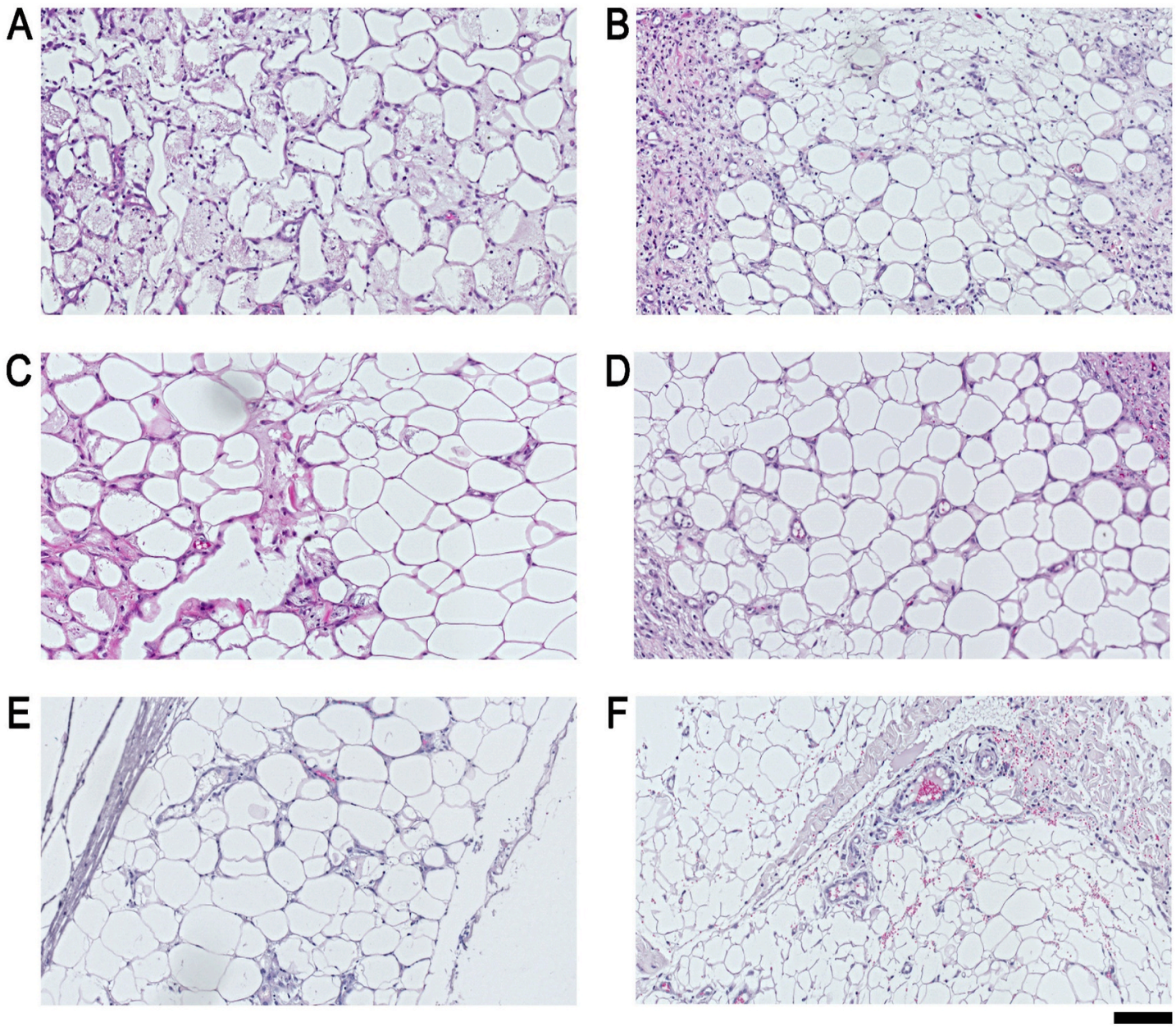

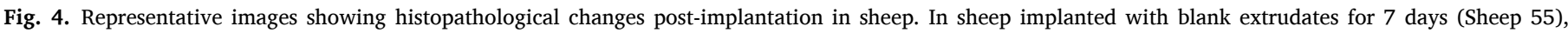

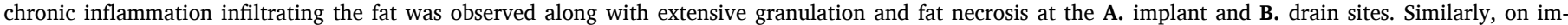

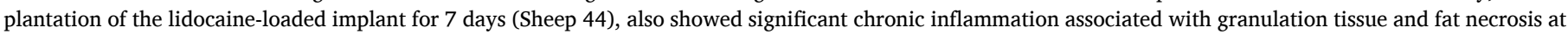

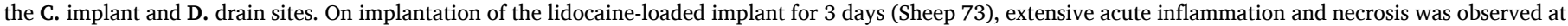
the E. implant and F. drain sites without any granulation tissue; scale bar $=100 \mu \mathrm{m}$.

reason, additional experiments were conducted over three days. The fibrous tracts were softer at three days in situ (Fig. 3C) and relatively equivalent to what was observed with the commercially available silicone drain (Fig. 3A). At necroscopy it was noted that after both three and 7 days the implants slid past the tissue on extraction with no overt trauma to the bowel, mesentery or omentum, suggesting that in vivo extraction would be equally atraumatic to the surrounding intraperitoneal content. Collectively, this data demonstrates that the described EVA implant does not cause an overt foreign body response up to three days.

Delivery of local anesthetic over three days has shown benefit in human patients by reducing opioid consumption and reducing pain following major abdominal surgery [9,32]. There may be additional benefit to extending this release period beyond three days. We did not test the suitability of the presented implant for use between three and 7 days, this could be the focus of future research, with the period of implantation matched to the specific surgical scenario. To reduce the foreign body response that was pronounced after 7 days, the formulation composition could be modified, or an additional polymer coating included. After 7 days the blank implant resulted in a less pronounced foreign body response compared to the drug loaded implant, this observation coupled with the known safety of lidocaine infusions [33], indicates that the presence myristic acid may be responsible for the inflammatory response. To extend the safe duration of use of the implant, in the future the formulation could be altered by swapping myristic acid
Table 5

Inflammation, granulation and fibrosis observed in response to the EVA coextrudates after 3 or 7 days of implantation. Data represented by mean (range).

\begin{tabular}{lllll}
\hline Duration of Implantation & Inflammation & \multicolumn{3}{l}{$\begin{array}{l}\text { Granulation and } \\
\text { Fibrosis }\end{array}$} \\
\hline ( $\mathrm{n}=$ number of animals per & Implant & Drain & Implant & Drain \\
group) & site & site & site & site \\
3 Days Drug Loaded, $\mathrm{n}=3$ & $3[2,3]$ & $3[3]$ & $0(0)$ & $0(0)$ \\
7 Days Drug Loaded, $\mathrm{n}=5$ & $3[1-3]$ & $3[1-3]$ & $2[1-4]$ & $2[1-4]$ \\
7 Days Blank, $\mathrm{n}=3$ & $3[1-3]$ & $1[1-3]$ & $3[2-4]$ & $2[2]$ \\
\hline
\end{tabular}

for another molecule with similar physical stabilisation properties, such as different fatty acids.

\subsection{Histopathology}

Histopathological analysis following paraffin embedding and microtomy showed chronic active inflammation with granulation (Fig. 4) at both implant and drain sites in sheep following 7 days of implantation. There with no statistical differences when comparing implant and silicone drain sites for lidocaine-loaded or blank implants following 7 days implantation (Table 5). After 3 days of implantation granulation and fibrosis was absent, although acute inflammation was still evident at both implant and drain site. Comparing data at 3 vs 7 days 

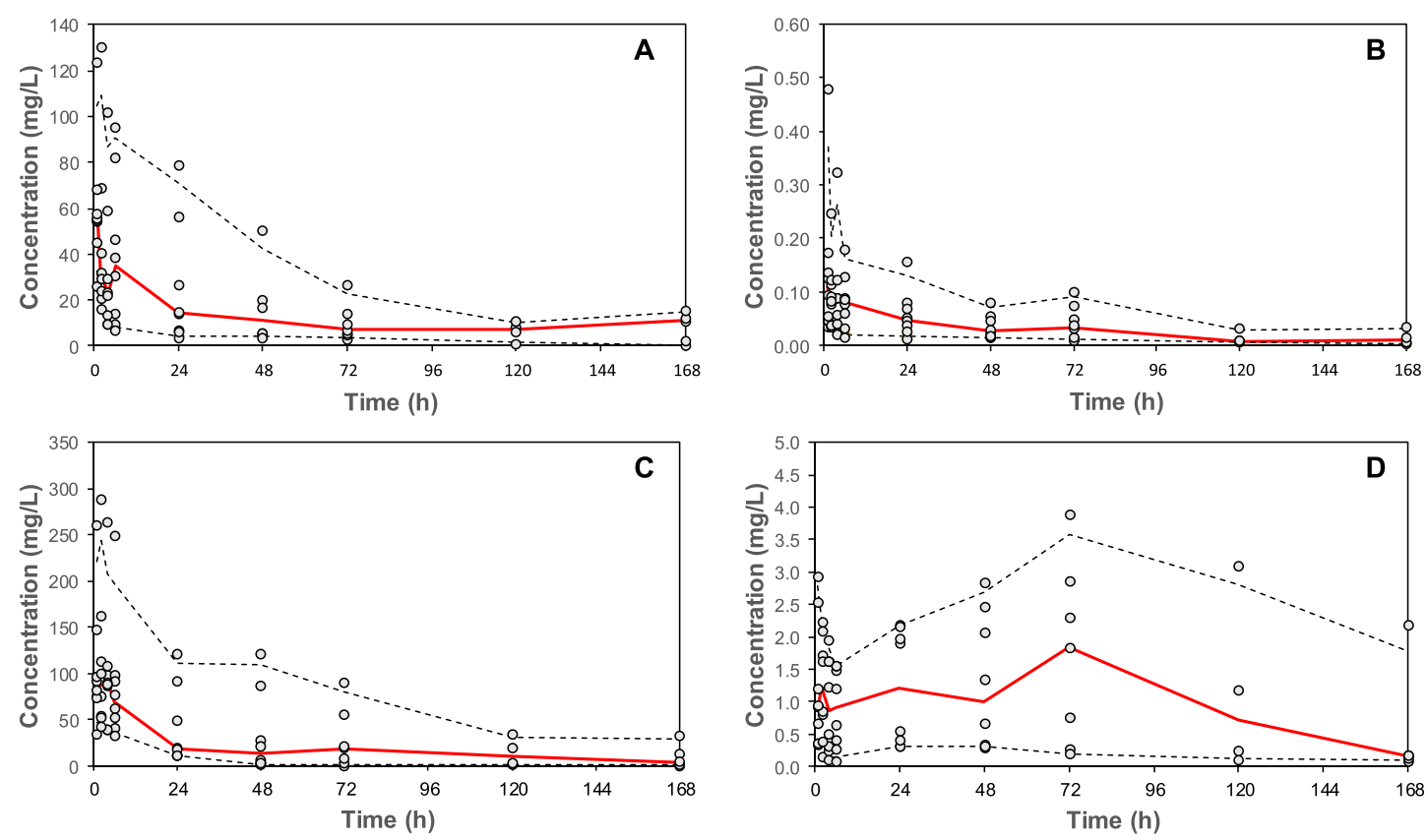

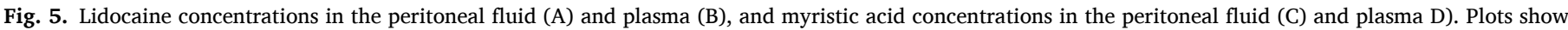

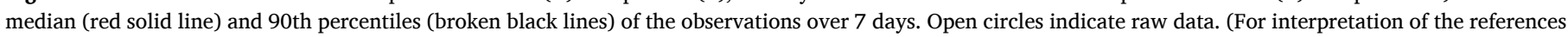
to colour in this figure legend, the reader is referred to the Web version of this article.)

Table 6

Pharmacokinetic parameter estimates for lidocaine.

\begin{tabular}{|c|c|c|c|}
\hline Parameter & Estimate & PPV & $95 \% \mathrm{CI}$ \\
\hline $\mathrm{F}$ & 0.95 Fix & - & - \\
\hline F_bol & 0.094 Fix & - & - \\
\hline Krel $\left(h^{-1}\right)$ & 0.025 Fix & - & - \\
\hline $\mathrm{Vp} / \mathrm{F}\left(\mathrm{L} .70 \mathrm{~kg}^{-1}\right)$ & 0.27 & 41.6 & $0.03,0.52$ \\
\hline F_elim & 0.43 & - & $0.18,0.56$ \\
\hline Tabs (h) & 0.147 & - & $0.02,0.22$ \\
\hline 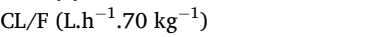 & 249 & 44.3 & $106.0,355.1$ \\
\hline $\mathrm{V} / \mathrm{F}\left(\mathrm{L} .70 \mathrm{~kg}^{-1}\right)$ & 10 & 261.5 & $0.1,17.8$ \\
\hline Peritoneal, Plasma ERR ADD $_{\left(\mathrm{mg} . \mathrm{L}^{-1}\right)}$ & $6.4,0.02$ & & \\
\hline Peritoneal, Plasma ERR PROP $_{\text {(\%) }}$ & $50.9,30.7$ & & \\
\hline
\end{tabular}

of implantation, granulation and fibrosis was statistically lower at both drain and implant sites after 3 days $(\mathrm{p}<0.05)$, while there were no statistical differences in inflammation. A foreign body response occurs for all implanted biomaterials, which inevitably evoke a host reaction, and is further influenced by the type of tissue enclosing the implant [34]. EVA is generally regarded as biocompatible and widely used in a number of medical devices and drug delivery systems, as previously mentioned. Hence, whilst all implanted materials will result in a foreign body response it is the speed and extent of this response that determines ultimately usability.

\subsection{Pharmacokinetics of lidocaine and myristic acid}

Lidocaine and myristic acid were measured in peritoneal fluid and blood at the first time point $(1 \mathrm{~h})$ indicating that release and absorption processes begin quickly following implantation. Lidocaine concentrations in both peritoneal fluid and blood slowly decreased over 7 days. Considerable inter-animal variation was noted, which is not unexpected [35]. Concentrations achieved in the local peritoneal environment were several orders of magnitude higher than in the blood (Fig. 5). Circulating blood concentrations were well below the reported toxic levels in humans at all time points [36].

In vitro data were best fitted using a first order release profile with offset and intercept. This gave an estimated $95 \%$ of lidocaine available
Table 7

Lidocaine and myristic acid remaining in extrudates after implantation for 3 or 7 days. Values are expressed as a \% remaining compared to the lidocaine loading levels before implantation (mean $\pm \mathrm{SD} ; \mathrm{n}=3$ discrete sections of implant were tested from each animal).

\begin{tabular}{llll}
\hline $\begin{array}{l}\text { Duration of Implantation } \\
\text { (drug loaded or blank) }\end{array}$ & SheepNumber & $\begin{array}{l}\text { Lidocaine\% } \\
\text { Remaining }\end{array}$ & $\begin{array}{l}\text { Myristic Acid\% } \\
\text { Remaining }\end{array}$ \\
\hline 3 days (drug loaded) & Sheep 38 & $10.47 \pm 0.49$ & $10.04 \pm 1.82$ \\
3 Days (drug loaded) & Sheep 73 & $18.31 \pm 3.16$ & $16.91 \pm 6.77$ \\
3 Days (drug loaded) & Sheep 42 & $18.58 \pm 0.83$ & $11.21 \pm 0.98$ \\
7 Days (drug loaded) & Sheep 44 & $4.22 \pm 0.51$ & $<4.00^{\mathrm{a}}$ \\
7 Days (drug loaded) & Sheep 10 & $2.57 \pm 0.56$ & $<4.00^{\mathrm{a}}$ \\
7 Days (drug loaded) & Sheep 30 & $1.36 \pm 0.10$ & $<4.00^{\mathrm{a}}$ \\
7 Days (drug loaded) & Sheep 40 & $0.80 \pm 0.33$ & $<4.00^{\mathrm{a}}$ \\
7 Days (drug loaded) & Sheep 54 & $0.90 \pm 0.10$ & $<4.00^{\mathrm{a}}$ \\
7 Days (blank) & Sheep 57 & - & - \\
\hline
\end{tabular}

${ }^{\text {a }}$ Concentration in samples was below the Limit of Quantification.

for release (F) from the implant, with $9.4 \%$ entering the peritoneal cavity by bolus input ( $\mathrm{F}_{-}$bol) and the remaining $90.6 \%$ entering via first order absorption. Final model parameter estimates are given in Table 6. Clearance (CL/F) from the central compartment, at $3.56 \mathrm{~L} / \mathrm{h} / \mathrm{kg}$, was similar to reported values $(2.82 \mathrm{~L} / \mathrm{h} / \mathrm{kg}$ for lidocaine in non-pregnant ewes) [37]. The volume of distribution parameter (V/F) was estimated at just $0.14 \mathrm{~L} / \mathrm{kg}$, much less than previous reports $(0.95-1.5 \mathrm{~L} / \mathrm{kg}$ ) [37]. Between subject variability for $\mathrm{V} / \mathrm{F}$ was high and confidence intervals for its precision wide, suggesting that this parameter was not well informed by the dataset. Visual predictive checks for the final model are given in Supplementary Figure 1 and show good overlay between model predicted and observed concentrations, albeit with some over-prediction of lidocaine in the peritoneal during the first $48 \mathrm{~h}$.

F: fraction of lidocaine released from the implant; Krel: first order rate constant of release from the implant; $\mathrm{F}_{-} b o l$ : fraction of lidocaine released instantaneously from the implant; $\mathrm{Vp} / \mathrm{F}$ : volume parameters of the peritoneal compartment; $F_{-}$elim: fraction of drug escaping elimination from the peritoneal cavity and passing directly to the central compartment; Tabs: half-life of first order absorption from peritoneal to plasma compartments; CL/F and V/F: clearance and volume parameters 


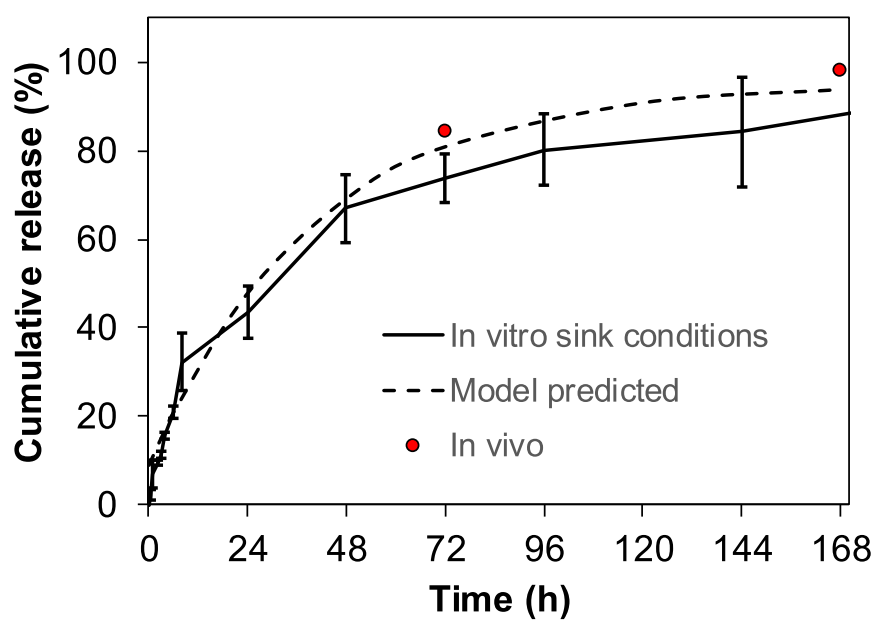

Fig. 6. Cumulative lidocaine release from the implant over 7 days. Plot shows in vitro release as obtained from a single strand of HME EVA (33\% VA) containing 20\% lidocaine in human peritoneal fluid as described in section 2.8 (solid black line); predicted in vivo release predicted using the final pharmacokinetic model (broken black line); and lidocaine released from the implant at days 3 and 7 in vivo as described in section 3.5 (solid circles).

relating to the central compartment. Population parameter variability (PPV) is given as a coefficient of variation; $E R_{A D D}$ and $E R_{P R O P}$ are additive and proportional residual unknown variability; $\mathrm{CI}$ is the confidence interval estimated using bootstrap methods and 1000 simulations. 'Fix' denote parameters that are assumed a priori from in vitro data and not estimated.

\subsection{Lidocaine and myristic acid remaining post-implantation}

The amount of lidocaine remaining after 3 and 7 days postimplantation is shown in Table 7. More than $80 \%$ of the lidocaine and myristic acid was released from the co-extrudates over the first 3 days, correlating with the observed concentrations in blood and peritoneal fluid. After 7 days, less than $5 \%$ of lidocaine remained in the coextrudates whilst myristic acid levels were too low to quantify by the LCMS-MS method. Recovery of lidocaine at 3 and 7 days was in line with what was expected based on in vitro release data and the pharmacokinetic model predicted release profiles (see Fig. 6). Release of lidocaine from the EVA matrix is governed by diffusion, which may be assisted to some extent by penetration of surrounding liquid media into the EVA matrix [38]. The process of diffusion is driven by concentration differences between the polymer carrier and release media, as the difference in concentration decreases over time the rate of release also decreases giving the release profile evident in Fig. 6, and resulting in levels in the sheep evident in Fig. 5.

\subsection{Evaluation of the implants pre and post-surgery}

\subsubsection{Tensile strength of the implant}

Tensile analysis of the implant revealed an increase in both the Young's modulus and tensile strength at break following in vivo implantation (Fig. 7). The increases in Young's modulus and tensile strength from before implantation to after 3 days implantation, and from 3 days implantation to 7 days implantation were statistically significant ( $p<0.05$ ). Young's modulus can be used to determine the stiffness of the implant, whilst tensile strength is an indication of the maximum stress the implant can withstand prior to breaking or failing. The EVA implants display sufficient mechanical strength to withstand removal when required. Interestingly, a similar increase in tensile properties has previously been reported with EVA-based mouth guards following contact with saliva [39]. Yet in contrast, a reduction in tensile strength was reported when EVA based polymeric systems were immersed to PBS solution at $37{ }^{\circ} \mathrm{C}$ [40].

The overall mechanical strength of the polymeric system does not only depend upon the polymer itself but is also influenced by the drug dispersed within the outer shell. Lidocaine has been reported to exert plasticizing effects on various polymers including poly(lactic-co-glycolic acid) and acrylates [41]. A similar phenomenon of increased EVA plasticization by lidocaine may have occurred with this investigated polymeric system. The blank implant before implantation had statistically greater tensile strength that the drug loaded implant before implantation. After 7 days of implantation there was no statistical difference in tensile strength at break for the drug loaded and blank implants. During implantation and subsequent drug release, the lidocaine content within the polymer decreases. This reduction in drug load may in turn, reduce the plasticization effect of lidocaine on EVA. The free volume between EVA chains is greater in the presence of plasticizers, allowing for greater chain flexibility and mobility. As such, the
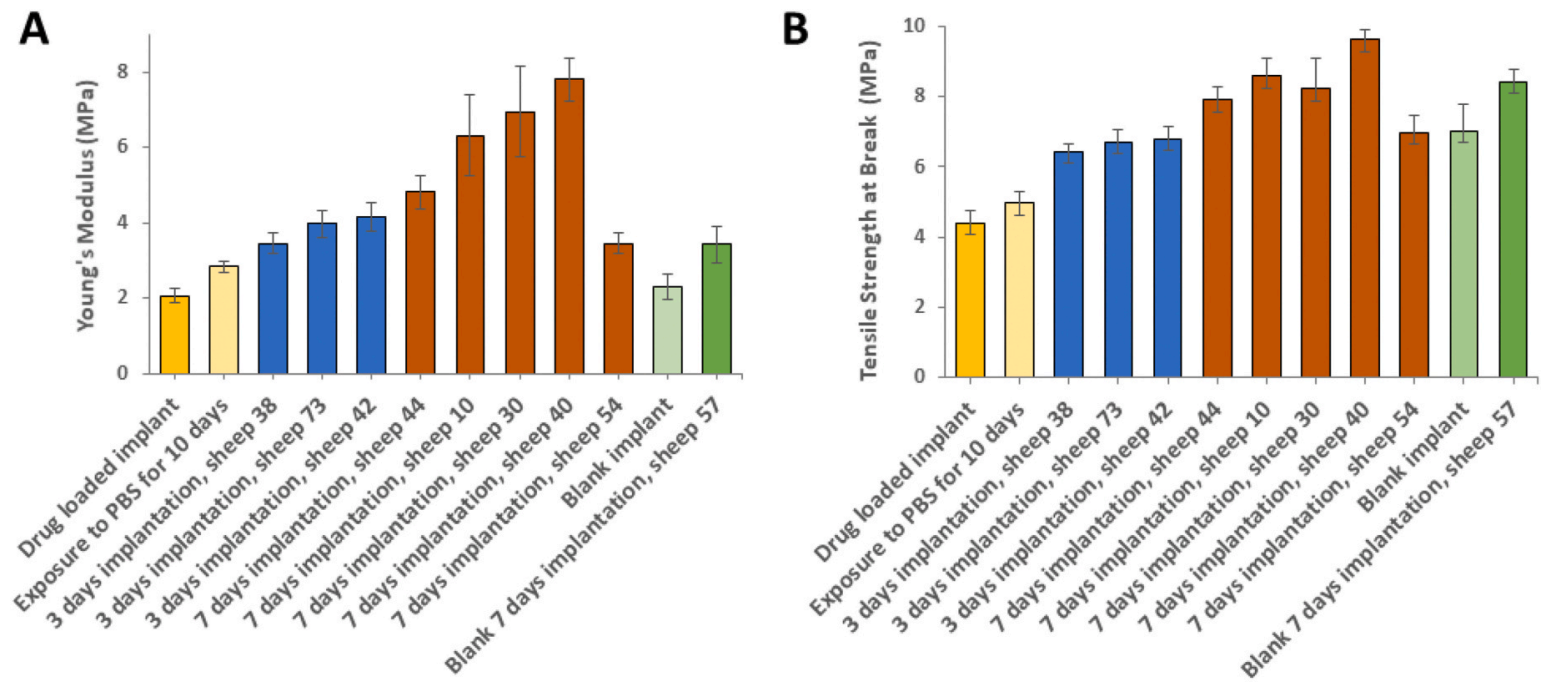

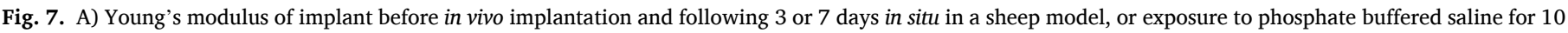

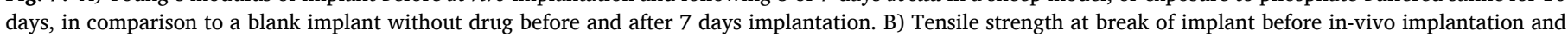

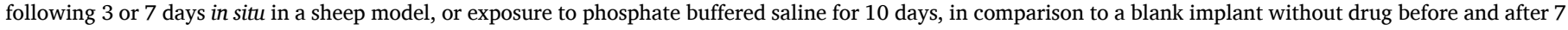
days implantation. Mean values reported with error bars representing standard deviation, $\mathrm{n}=5$. 


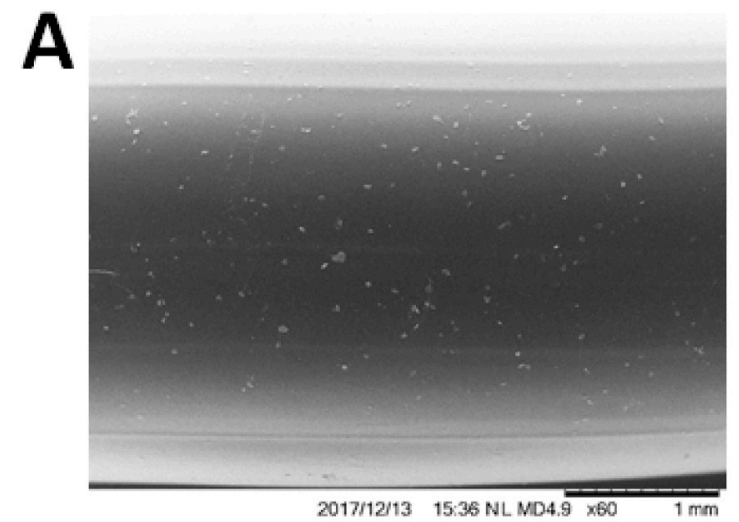

B

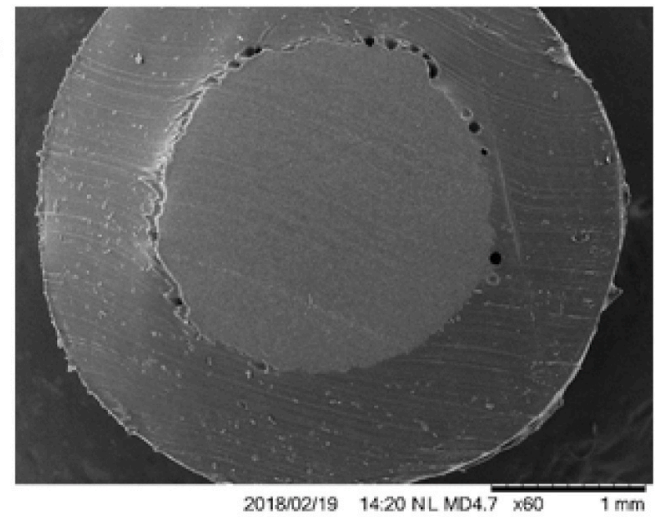

C
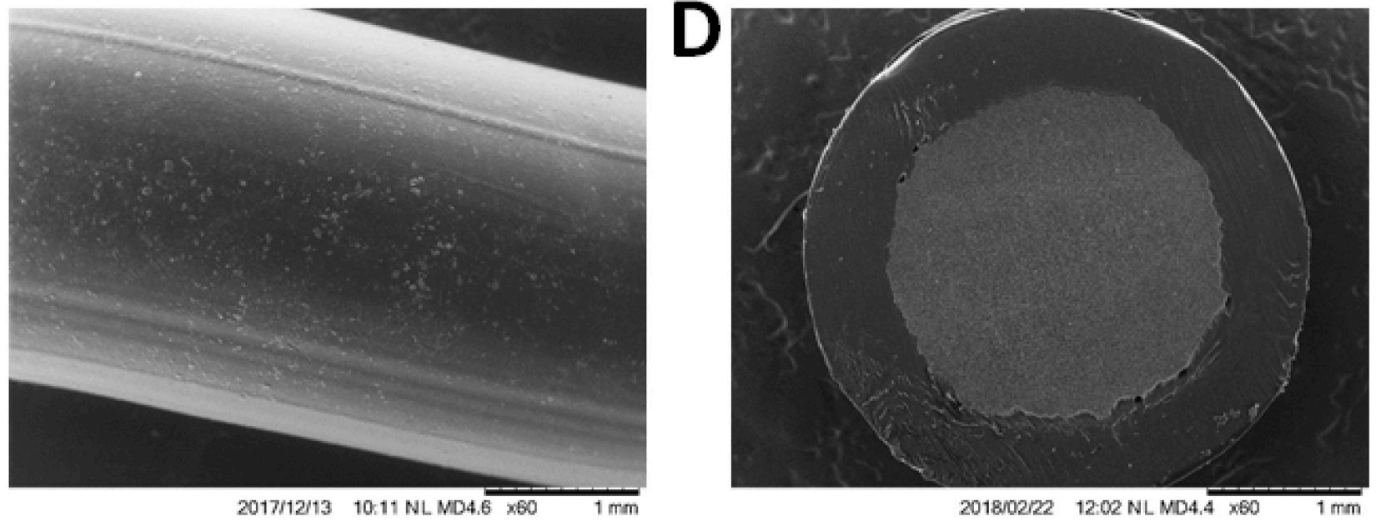

E

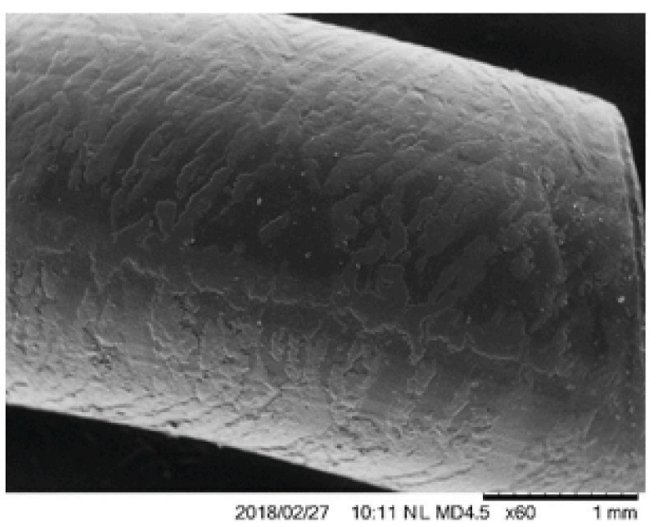

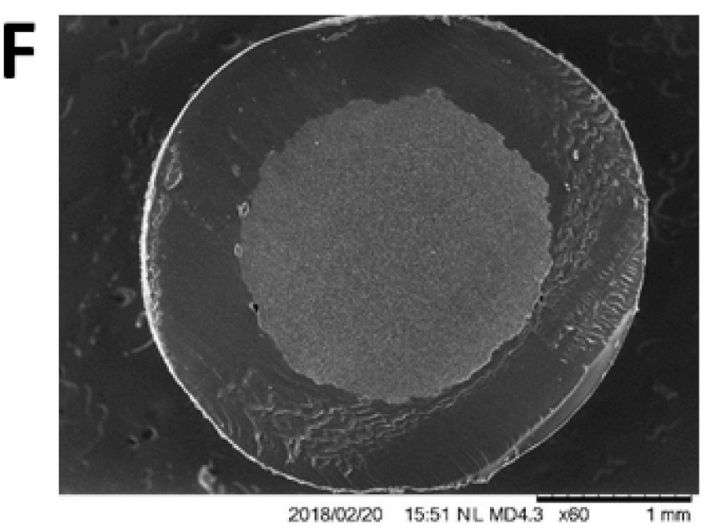

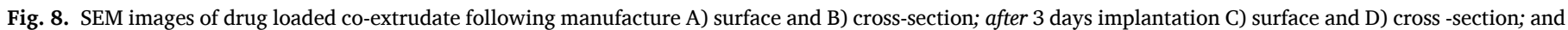
after 7 days implantation E) surface and F) cross-section. Images acquired at $60 \times$ magnification; scale bar $=1 \mathrm{~mm}$.

plasticized EVA would require less force and resistance to deform and a lower tensile strength and Young's modulus value. With drug release reducing this plasticization effect, this would explain the increased tensile parameters noted at the end of the in vivo experiments [42].

\subsubsection{Surface morphology}

Scanning electron micrographs of the co-extrudates acquired before and after implantation are shown in Fig. 8. As observed in the crosssectional images, the inner $\mathrm{BaSO}_{4}$ loaded core is clearly distinguishable from the drug loaded outer shell. Some pores are evident between the core and shell layers which can be attributed to the manufacture process. Notably, the surface of the implants whilst smooth before implantation, appeared to increase in roughness by day 3 postimplantation, and to an even greater extent by day 7 . This change in roughness correlates with granulation and fibrosis that became evident after 7 days of implantation.

\section{Conclusions}

In the present work, we have used an ovine model to describe a novel intraperitoneal EVA implant to enable sustained lidocaine delivery over several days. Tensile analysis has shown the implant to possess sufficient mechanical strength to facilitate administration and removal procedures. The movement of lidocaine within the peritoneal fluid and circulating plasma was observed and modelled, demonstrating high local levels and several fold lower circulating levels at non-toxic concentrations. A pharmacokinetic model incorporating in vitro release data described lidocaine concentrations in both peritoneal and plasma compartments, predicting similar release to that suggested by lidocaine concentrations remaining in the device after 3 and 7 days in situ. This pharmacokinetic model can be used to inform future studies of the device in vivo.

A similar inflammatory response was observed between the current device and an already commercially-used silicone drain after three days implantation. After 7 days of implantation the surface of the device roughened and significant fibrin tracts formed in the peritoneal cavity. 
Future work will be needed to evaluate the evolution of the foreign body response between three and 7 days. To translate this technology for applications requiring more than three days of drug delivery the formulation may need to be modified to reduce the granulation and fibrosis observed after 7 days.

This implant addresses the need for non-opioid modalities for postoperative pain relief and can safely deliver sufficient doses of lidocaine to the peritoneal space for up to three days, expected to achieve a clinical effect in humans [10-12]. This technology is now positioned for first in human trials and in the future can be modified for use with other active agents to meet a range of clinical needs.

\section{Funding Source}

This work was supported by the Return on Science Fund [33,013] and the Auckland Medical Research Foundation [1114011].

\section{CRediT authorship contribution statement}

Darren Svirskis: Conceptualization, Methodology, Formal analysis, Writing - original draft, Writing - review \& editing, Visualization, Supervision, Project administration, Funding acquisition. Georgina Procter: Investigation, Methodology, Formal analysis. Manisha Sharma: Conceptualization, Methodology, Writing - review \& editing, Supervision, Project administration, Funding acquisition. Prabhat Bhusal: Conceptualization, Methodology, Formal analysis, Investigation, Writing - review \& editing, Visualization. Anusha Dravid: Writing - original draft, Visualization. Wiremu MacFater: Methodology, Investigation, Writing - review \& editing. Ahmed Barazanchi: Methodology, Investigation, Writing - review \& editing. Laura Bennet: Methodology, Writing - review \& editing. Kaushik Chandramouli: Investigation, Writing - review \& editing. Sree Sreebhavan: Methodology, Investigation, Writing - review \& editing. Priyanka Agarwal: Methodology, Formal analysis, Investigation, Writing - original draft, Writing - review \& editing, Visualization. Satya Amirapu: Methodology, Formal analysis, Investigation, Writing - review \& editing. Jacqueline A. Hannam: Methodology, Formal analysis, Writing - original draft, Writing - review \& editing, Visualization. Gavin P. Andrews: Conceptualization, Writing - review \& editing. Andrew Hill: Conceptualization, Methodology, Writing - review \& editing, Supervision, Project administration, Funding acquisition. David S. Jones: Conceptualization, Methodology, Formal analysis, Writing - review \& editing, Visualization, Supervision, Project administration, Funding acquisition.

\section{Declaration of competing interest}

The authors declare that they have no known competing financial interests or personal relationships that could have appeared to influence the work reported in this paper.

\section{Acknowledgements}

We thank Maree Schollum, Vanessa Hawkins and Mahima Bansal for providing their expertise in facilitating the surgical anesthesia and preand post-operative care of the animals; Tao $\mathrm{Yu}$ in producing extrudate samples and obtaining tensile data; and Matt Taylor and Jeff Harrison for useful discussion concerning dosing and form of the formulation. The SEM data reported in this paper were obtained by Hilary Holloway at the Biomedical Imaging Research Unit (BIRU), operated and funded by Technical Services (Faculty of Medical and Health Sciences, University of Auckland).

\section{Appendix A. Supplementary data}

Supplementary data to this article can be found online at https://doi. org/10.1016/j.biomaterials.2020.120409.

\section{Data availability}

The raw/processed data required to reproduce these findings cannot be shared at this time due to technical or time limitations.

\section{References}

[1] T.G. Weiser, A.B. Haynes, G. Molina, S.R. Lipsitz, M.M. Esquivel, T. Uribe-Leitz, et al., Estimate of the global volume of surgery in 2012: an assessment supporting improved health outcomes, Lancet 385 (2015) S11.

[2] T.J. Gan, Poorly controlled postoperative pain: prevalence, consequences, and prevention, J. Pain Res. 10 (2017) 2287-2298.

[3] S. Harsoor, Emerging concepts in post-operative pain management, Indian J. Anaesth. 55 (2) (2011) 101-103.

[4] K.V. Kelkar, Post-operative pulmonary complications after non-cardiothoracic surgery, Indian J. Anaesth. 59 (9) (2015) 599-605.

[5] M.D. Neuman, B.T. Bateman, H. Wunsch, Inappropriate opioid prescription after surgery, Lancet (London, England) 393 (10180) (2019) 1547-1557.

[6] L.S. Nelson, D.N. Juurlink, J. Perrone, Addressing the opioid epidemic, J. Am. Med. Assoc. 314 (14) (2015) 1453-1454.

[7] R.S. Sinatra, J.S. Jahr, J.M. Watkins-Pitchford, The Essence of Analgesia and Analgesics, Cambridge University Press, 2010.

[8] D.E. Becker, K.L. Reed, Local anesthetics: review of pharmacological considerations, Anesth. Prog. 59 (2) (2012) 90-103.

[9] A. Kahokehr, T. Sammour, M. Soop, A.G. Hill, Intraperitoneal local anaesthetic in abdominal surgery-a systematic review, ANZ J. Surg. 81 (4) (2011) 237-245.

[10] A. Kahokehr, T. Sammour, R. Vather, M. Taylor, F. Stapelberg, A.G. Hill, Systemic levels of local anaesthetic after intra-peritoneal application - a systematic review 38 (4) (2010) 623-638.

[11] T.H. Kim, H. Kang, J.H. Hong, J.S. Park, C.W. Baek, J.Y. Kim, et al., Intraperitoneal and intravenous lidocaine for effective pain relief after laparoscopic appendectomy: a prospective, randomized, double-blind, placebo-controlled study, Surg. Endosc. 25 (10) (2011) 3183-3190.

[12] S.Y. Yang, H. Kang, G.J. Choi, H.Y. Shin, C.W. Baek, Y.H. Jung, et al., Efficacy of intraperitoneal and intravenous lidocaine on pain relief after laparoscopic cholecystectomy 42 (2) (2014) 307-319.

[13] M. Grissinger, Improved safety needed in handling elastomeric reservoir balls used for pain relief, P T 38 (5) (2013) 243-245.

[14] S.L. Brown, E.R.N. Morrison Audrey, Local anesthetic infusion pump systems adverse events reported to the food and drug administration, Anesthesiology: The Journal of the American Society of Anesthesiologists. 100 (5) (2004) 1305-1307.

[15] A. Koogler, G. Amusa, M. Kushelev, A. Lawrence, L. Carlson, K. Moran, Elastomeric pump malfunction resulting in over-infusion of local anesthetic 7 (2019), 2050313 X18823928.

[16] J.S. Rose, J.M. Neal, D.J. Kopacz, Extended-duration analgesia: update on microspheres and liposomes, Reg. Anesth. Pain Med. 30 (3) (2005) 275-285.

[17] S.A. Stewart, J. Domínguez-Robles, R.F. Donnelly, E. Larrañeta, Implantable polymeric drug delivery devices: classification, manufacture, materials, and clinical applications, Polymers 10 (12) (2018) 1379.

[18] C. Schneider, R. Langer, D. Loveday, D. Hair, Applications of ethylene vinyl acetate copolymers (EVA) in drug delivery systems, J. Contr. Release 262 (2017) 284-295.

[19] R.H. Stewart, S. Novak, Introduction of the ocusert ocular system to an ophthalmic practice, Ann. Ophthalmol. 10 (3) (1978) 325-330.

[20] B.B. Pharriss, R. Erickson, J. Bashaw, S. Hoff, V.A. Place, A. Zaffaroni, Progestasert: a uterine therapeutic system for long-term contraception: I. Philosophy and clinical efficacy, Fertil. Steril. 25 (11) (1974) 915.

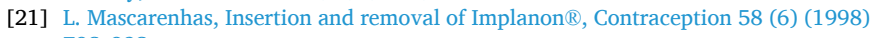
79S-83S.

[22] T.M.T. Mulders, T.O.M. Dieben, Use of the novel combined contraceptive vaginal ring NuvaRing for ovulation inhibition, Fertil. Steril. 75 (5) (2001) 865-870.

[23] J.M. Litch, M. Encarnacion, S. Chen, J. Leonard, T.L. Burkoth, Use of the polymeric matrix as internal standard for quantitation of in vivo delivery of tetracycline HCI from Actisite $\mathbb{R}$ tetracycline fiber during periodontal treatment, J. Periodontal. Res. 31 (8) (1996) 540-544.

[24] C. Spaulding, E. Teiger, P. Commeau, O. Varenne, E. Bramucci, M. Slama, et al., Four-year follow-up of TYPHOON (trial to assess the use of the CYPHer sirolimuseluting coronary stent in acute myocardial infarction treated with BalloON angioplasty), JACC Cardiovasc. Interv. 4 (1) (2011) 14-23.

[25] Vitrasert (TM), a Sterile Intravitreal Implant, for Sustained Intravitreal Delivery of Ganciclovir for the Treatment of CMV Retinitis, in: R.C. Kanner, J. Gordon (Eds.), Abstracts of Papers of the American Chemical Society, vol. 1155, AMER CHEMICAL SOC, 16TH ST, NW, WASHINGTON, DC, 1997, 20036.

[26] P. Bhusal, M. Sharma, J. Harrison, G. Procter, G. Andrews, D.S. Jones, et al., Development, validation and application of a stability indicating HPLC method to quantify lidocaine from polyethylene-co-vinyl acetate (EVA) matrices and biological fluids, Journal of Chomatographic Science 34 (1) (2017) 1-7.

[27] P. Bhusal, J.L. Rahiri, B. Sua, J.E. McDonald, M. Bansal, S. Hanning, et al., Comparing human peritoneal fluid and phosphate-buffered saline for drug delivery: do we need bio-relevant media? Drug Deliv Transl Res 8 (3) (2018) $708-718$.

[28] C. Kilkenny, W.J. Browne, I.C. Cuthill, M. Emerson, D.G. Altman, Improving bioscience research reporting: the ARRIVE guidelines for reporting animal research, PLoS Biol. 8 (6) (2010), e1000412. 
[29] S.I. Seldinger, Catheter replacement of the needle in percutaneous arteriography. A new technique, Acta Radiol. Suppl. 434 (2008) 47-52.

[30] B. Efron, R. Tibshirani, Bootstrap methods for standard errors, confidence intervals, and other measures of statistical accuracy, Stat. Sci. 1 (1986) 54-77.

[31] T.H. Nguyen, M.S. Mouksassi, N. Holford, N. Al-Huniti, I. Freedman, A.C. Hooker et al., Model evaluation of continuous data pharmacometric models: metrics and graphics, CPT Pharmacometrics Syst. Pharmacol. 6 (2) (2017) 87-109.

[32] A. Perniola, F. Fant, A. Magnuson, K. Axelsson, A. Gupta, Postoperative pain after abdominal hysterectomy: a randomized, double-blind, controlled trial comparing continuous infusion vs patient-controlled intraperitoneal injection of local anaesthetic, Br. J. Anaesth. 112 (2) (2014) 328-336.

[33] R. Patel, J.C.A. Carvalho, K. Downey, M. Kanczuk, P. Bernstein, N. Siddiqui, Intraperitoneal instillation of lidocaine improves postoperative analgesia at cesarean delivery: a randomized, double-blind, Placebo-Controlled Trial 124 (2) (2017) 554-559.

[34] E. Mariani, G. Lisignoli, R.M. Borzì, L. Pulsatelli, Biomaterials: foreign bodies or tuners for the immune response? Int. J. Mol. Sci. 20 (3) (2019) 636.

[35] H.S. Al-Sallami, S.L. Cheah, S.Y. Han, J. Liew, J. Lim, M.A. Ng, et al., Betweensubject variability: should high be the new normal? Eur. J. Clin. Pharmacol. 70 (11) (2014) 1403-1404.
[36] B. Cox, M.E. Durieux, M.A.E. Marcus, Toxicity of local anaesthetics, Best Pract. Res. Clin. Anaesthesiol. 17 (1) (2003) 111-136.

[37] A.C. Santos, H. Pedersen, H.O. Morishima, M. Finster, G.R. Arthur, B.G. Covino, Pharmacokinetics of lidocaine in nonpregnant and pregnant ewes, Anesth. Analg. 67 (12) (1988) 1154-1158.

[38] A. Almeida, S. Possemiers, M.N. Boone, T.D. Beer, T. Quinten, L.V. Hoorebeke, et al., Ethylene vinyl acetate as matrix for oral sustained release dosage forms produced via hot-melt extrusion, Eur. J. Pharm. Biopharm. 77 (2) (2011) 297-305.

[39] N.P. Coto, RBe Dias, R.A. Costa, T.F. Antoniazzi, EPCd Carvalho, Mechanical behavior of Ethylene Vinyl Acetate copolymer (EVA) used for fabrication of mouthguards and interocclusal splints, Braz. Dent. J. 18 (2007) 324-328.

[40] A.F. Osman, A.M. Alakrach, H. Kalo, W.N.W. Azmi, F. Hashim, In vitro biostability and biocompatibility of ethyl vinyl acetate (EVA) nanocomposites for biomedical applications, RSC Adv. 5 (40) (2015) 31485-31495.

[41] P.C. Chen, Y.J. Park, L.C. Chang, D.S. Kohane, R.H. Bartlett, R. Langer, et al., Injectable microparticle-gel system for prolonged and localized lidocaine release. I. In vitro characterization, J. Biomed. Mater. Res. 70 (3) (2004) 412-419.

[42] H. Lim, S.W. Hoag, Plasticizer effects on physical-mechanical properties of solvent cast Soluplus $®$ films, AAPS PharmSciTech 14 (3) (2013) 903-910. 